\title{
A Manufacturing Industry Case Study: ABC and HML Analysis for Inventory Management
}

\author{
Pragati Jadhav ${ }^{1 *}$, Maheshwar Jaybhaye ${ }^{2}$ \\ ${ }^{I}$ M.Tech. Student, Department of Manufacturing Engineering and Industrial Management, College of \\ Engineering, Pune, India \\ ${ }^{2}$ Associate Professor, Department of Manufacturing Engineering and Industrial Management, College of \\ Engineering, Pune, India \\ *Corresponding author: pragatigj18.prod@coep.ac.in
}

\begin{abstract}
This article is a contextual analysis of $\mathrm{ABC}$ and HML examination of inventory control methods for an effective Inventory administration framework in the assembling business of India. The organization needs to control its inventory expense, so it utilized various kinds of inventory methods to control this. There are various strategies, for example, ABC, HML, VED, XYZ and $\mathrm{S}-\mathrm{O}-\mathrm{S}$. In the $\mathrm{ABC}$ analysis, things are classifications in classifications $\mathrm{A}, \mathrm{B}, \mathrm{C}$ as per the utilization of the all-out expense. In the HML analysis, things are classifications in $\mathrm{H}, \mathrm{M}, \mathrm{L}$ classification as per the unit cost. Information assortment is chiefly a year through the head supervisor of the store and other work force associated with the Inventory control activity of the assembling business.
\end{abstract}

Keywords: ABC \& HML analysis, Inventory, Inventory Management.

\section{Introduction}

In India, the quantity of little and enormous assembling organizations is expanding step by step. The specialists of assembling organizations are accustomed to dealing with their organizations in the customary manner with little or more involvement with the Inventory control framework. With the present unsure economy, organizations are searching for elective strategies to remain in front of their opposition by viably expanding deals and diminishing pointless expenses. Absence of Products inaccessibility seriously influences the degree of consumer loyalty, which is the primary driver of any business. All associations keep up a huge number of various sorts of Inventory, which dangers losing viable Inventory administration. To beat these issues, appropriate Inventory classification is required. There are various kinds of Inventory control examination procedures, for example, $\mathrm{ABC}$, HML, VED, S-O-S, and so on. Here we will zero in on ABC and HML analysis strategies.

Expanding the quantity of things in Inventory is an issue and requires severe controls. Verma (2010) gave a few arrangements, for example, SIM-particular Inventory administration comprising of a Pareto examination ABC analysis, a criticality analysis VED examination, a development examination FSN examination and an accessibility analysis
SED, GOLF, SOS, and so on to fulfill the clashing premiums of deciding the fitting add up to purchase and the base head immediately. In 1987 an article named "The applying numerous models ABC analysis" whose aftereffects of utilizing various $\mathrm{ABC}$ rules Analyzes gave to arrange capacity Inventory. The examinations in this article show that administrators can utilize both "cost models" and "No cost rules" in Inventory room grouping Inventory and define explicit arrangements utilizing various measures for overseeing distribution center Inventory.

As per Mitra, Pattanayak and Bhowmik (2013), the needs of the articles change as indicated by the various strategies of Inventory examination. The choice to choose the method that will profit them is up to administration. Kumar and Anas (2013) utilized an ABC analysis to deal with the supplies of numerous items from bikes India Ltd. The point of the analysis was to advance superior materials the executives strategy that would influence the organization's benefits.

Chen, Hung, Fu and Peng (2012) built up an ABC analysis model for Inventory control of numerous items. Ravinder and Misra (2014) zeroed in on the focal spot of ABC multi-rules examination in reading material. Customarily, the $\mathrm{ABC}$ analysis has been founded on the main standard: the incentive in dollars. Notwithstanding, the creators recommended that other models ought to be thought of: conveyance time, thing criticality, sturdiness, extraordinariness, repairability, Inventory limit, shared characteristic, substitutability, number of providers, mode and cost of transportation, likelihood of out of date quality or decay, and amounts of parts forced by providers, and so forth. Hatefi, Torabi and Bagheri (2014) introduced a changed straight advancement strategy that causes Inventory chiefs to order things in Inventory within the sight of subjective and quantitative rules with no subjectivity. Interest in retail location Inventorys speaks to roughly $70-80 \%$ of the absolute resources and working capital. A little sparing in Inventory will mirror crucial overall revenue of the association (Rambabu and Malyadri, 2014). The adequacy of Inventory control, to a huge degree, impacts business adaptability. Along these lines, incapable methods can prompt uneven, here and there exhausted or over-burden Inventory, requiring extreme 
speculation. These failures will at last negatively affect the association's benefits. In this article, four methods, for example, $\mathrm{EOQ}, \mathrm{ABC}$ analysis, wellbeing Inventory, and HML are examined for smooth Inventory administration that will limit overload and unavailable issues and give relative significance of things in Inventory.

\section{Objectives}

- Common objective: 1) Classify the things in Inventory in classes A, B, C. 2) Classify the things in Inventory in classes $\mathrm{H}, \mathrm{M}, \mathrm{L}$.

- Primary Objectives: The essential goal of this examination is to limit the expense of Inventory.

\section{Methodology}

There are various sorts of Inventory control examination procedures, for example, ABC, HML, XYZ, VED, S-O-S and GOLF, and so on we will be focus on ABC and HML analysis strategies.

\section{A. ABC analysis}

Always Better Control (ABC) analysis (likewise called "specific Inventory control") is a generally utilized Inventory classification strategy for overseeing put away material that should be overseen in an unexpected way. This procedure depends on the Pareto standard or the 80/20 principle and works by partitioning the components into three classes $\mathrm{A}, \mathrm{B}$ and $\mathrm{C}$ arranged by significance. "A" shows components that are extravagant and require severe control, components "B" are significant and require moderate control, components " $\mathrm{C}$ " are less significant than "An" and "B". The fundamental target of this grouping framework is to cause managers to notice the little basic number (components A) and not to the inconsequential number (components $\mathrm{C}$ ). Table 1 shows the rough division of this method. The estimation of the yearly utilization of various articles for the $\mathrm{ABC}$ order plot is determined as follows:

Annual consumption $=$ annual demand $\times$ unit price

Table 1

Rules of $\mathrm{ABC}$ analysis

\begin{tabular}{|l|l|l|l|}
\hline Category & $\%$ of items & $\%$ of item value & Control \\
\hline Class A items & About $15 \%$ & About 70\% & Maximum \\
\hline Class B items & About 30\% & About 20\% & Moderate \\
\hline Class C items & About 55\% & About 10\% & Minimum \\
\hline
\end{tabular}

\section{B. Procedures for $A B C$ analysis}

To play out the $\mathrm{ABC}$ analysis, four stages are vital:

1. Prepare the rundown of things and ascertain their unit value, yearly interest, yearly use and yearly use rate.

2. Organize things to lessen their yearly use.

3. Calculate the amassed yearly use, and afterward order the Inventory thing.

4. Draw the diagram dependent on "combined yearly utilization", at that point sort things in inventory.

\section{HML analysis}

The high, medium and low (HML) analysis is like the ABC examination, then again, actually the thing that matters is that rather than the yearly utilization esteem utilized in the $\mathrm{ABC}$ order, the expense per unit basis is utilized in HML analysis. This procedure depends on the Pareto standard or the 80/20 principle. The articles remembered for this arrangement conspires are grouped in slipping request of their unit cost. Arrangement of things dependent on unit cost is completely chosen by the board. It assists directors with settling on buying strategy choices, which implies that H\&M things ought not to be requested more than the necessary amount. The recurrence of Inventory checks is likewise set off by this technique. The most significant things require continuous Inventory checking.

\section{Procedure for HML analysis}

To perform HML examination, following advances are important:

1. Prepare the thing list and ascertain its unit cost, yearly interest, yearly use and the level of unit cost.

2. Arrange things in slipping request of their unit cost.

3. Calculate the aggregate unit cost, and afterward sort the thing into Inventory.

4. The organization at that point sets the slice lines to settle on three classes.

5. Draw the diagram based on "total unit expenses", and afterward rank things in inventory.

\section{Case Study}

\section{A. Study for $A B C$ analysis}

1. Prepare the thing list and ascertain its unit value, yearly interest, yearly use and yearly use rate).

2. Arrange the things in sliding request of their yearly use.

3. Calculate the collected yearly utilization, and afterward characterize the Inventory thing.

4. Draw the chart dependent on "total yearly utilization", at that point sort things in inventory.

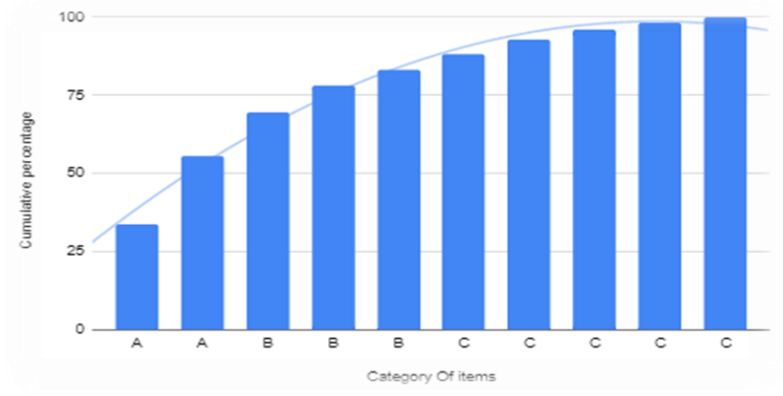

Fig. 1. ABC analysis on the basis of cumulative of annual usage

\section{B. Study for HML analysis}

1. Prepare the thing list and ascertain its unit cost, yearly interest, yearly use and the level of unit cost.

2. Order the things in sliding request of their unit cost.

3. Calculate the gathered unit cost, and afterward order the 
Volume-3, Issue-9, September-2020

\section{IJRESM journals.resaim.com/ijresm | ISSN (Online): 2581-5792 | RESAIM Publishing}

Table 2

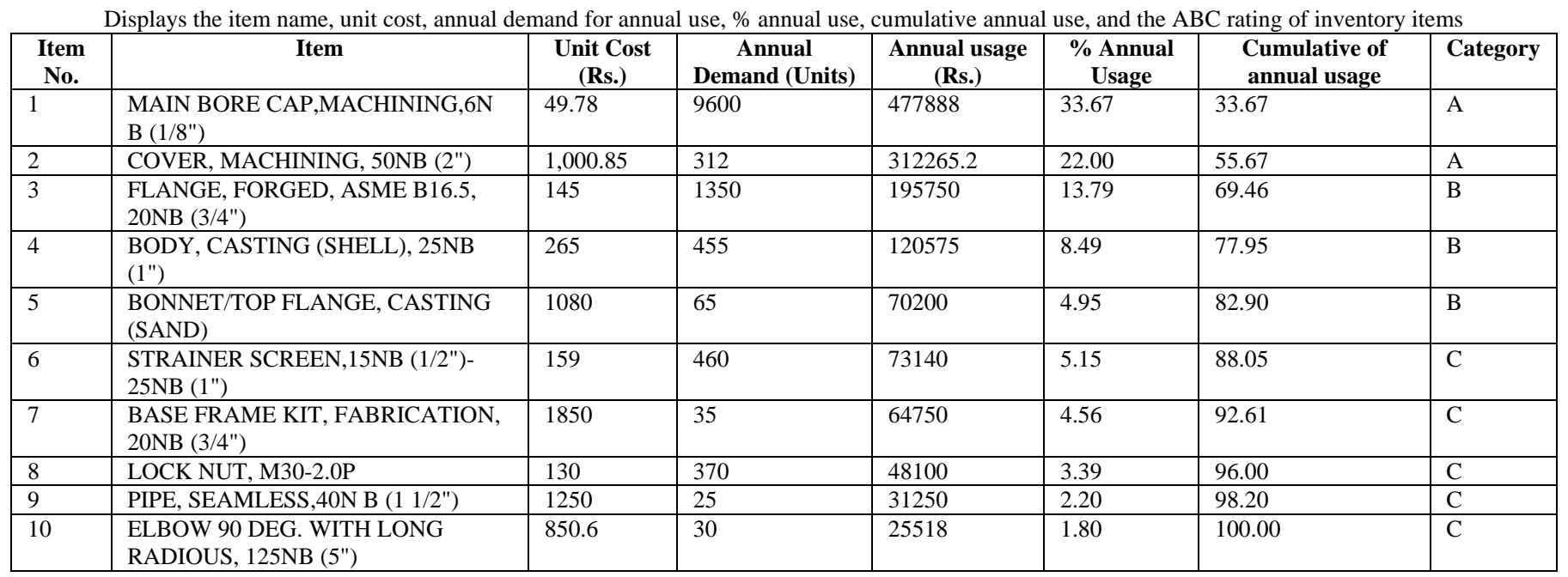

Table 3

Shows name of item, unit cost, annual demand, and annual usage, $\%$ unit cost, cumulative of unit cost and HML classification of inventory items

\begin{tabular}{|c|c|c|c|c|c|c|}
\hline $\begin{array}{c}\text { Item } \\
\text { No. }\end{array}$ & Item & Unit Cost & $\begin{array}{c}\text { Annual Demand } \\
\text { (Units) }\end{array}$ & $\begin{array}{c}\text { Annual } \\
\text { Usage(Rs.) }\end{array}$ & $\begin{array}{c}\text { \% Unit } \\
\text { Cost }\end{array}$ & Category \\
\hline 9 & PIPE, SEAMLESS, 40NB (11/2") & 1250 & 25 & 31250 & 18.44 & $\mathrm{M}$ \\
\hline 5 & BONNET/TOP FLANGE, CASTING (SAND) & 1080 & 65 & 70200 & 15.93 & $\mathrm{M}$ \\
\hline 10 & ELBOW 90 DEG. WITH LONG RADIOUS, 125NB (5") & 850.6 & 30 & 25518 & 12.55 & $\mathrm{~L}$ \\
\hline 4 & BODY, CASTING (SHELL), 25NB (1") & 265 & 455 & 120575 & 3.91 & $\mathrm{~L}$ \\
\hline 6 & STRAINER SCREEN,15NB (1/2")- 25NB (1") & 159 & 460 & 73140 & 2.35 & $\mathrm{~L}$ \\
\hline 1 & MAIN BORE CAP, MACHINING,6NB (1/8") & 49.78 & 9600 & 477888 & 0.73 & $\mathrm{~L}$ \\
\hline
\end{tabular}

thing in Inventory.

4. The organization builds up the slice lines to choose three classifications.

5. Draw the chart based on "combined unit expenses", and afterward rank things in Inventory.

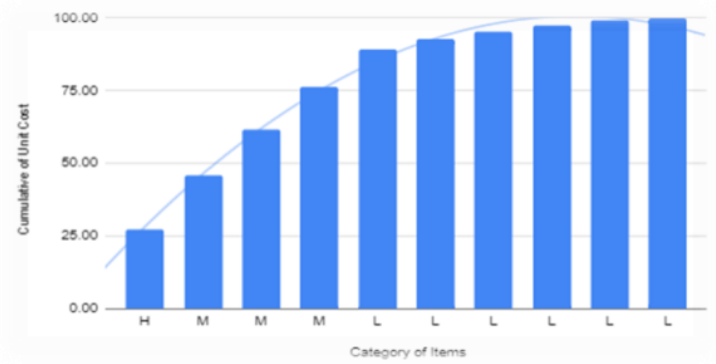

Fig. 2. HML analysis on the basis of cumulative of annual usage

\section{Results}

A. Result for $A B C$ analysis

Table 4

The result of $\mathrm{ABC}$ analysis

\begin{tabular}{|l|l|l|l|l|}
\hline Category & $\begin{array}{c}\text { Annual } \\
\text { Usage }\end{array}$ & $\begin{array}{c}\text { \% Annual } \\
\text { Usage }\end{array}$ & $\begin{array}{c}\text { Annual } \\
\text { Demand }\end{array}$ & $\begin{array}{c}\text { \% Annual } \\
\text { Demand }\end{array}$ \\
\hline A & 790153.2 & 55.67 & 2 & 20 \\
\hline B & 386525 & 27.23 & 3 & 30 \\
\hline C & 242758 & 17.10 & 5 & 50 \\
\hline Total & 1419436.2 & 100 & 10 & 100 \\
\hline
\end{tabular}

The ABC analysis based on\% of annual demand is illustrated in figure 3 .

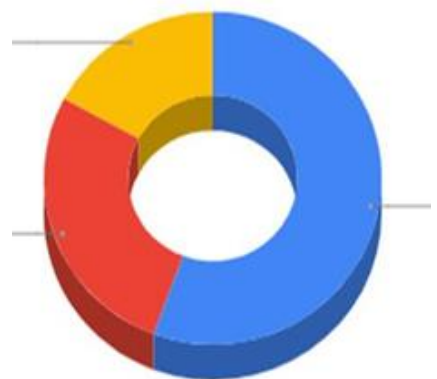

Fig. 3. Percent item annual usage of $A B C$ analysis

$\mathrm{ABC}$ analysis on the basis of \% annual demand is shown in figure 4 .

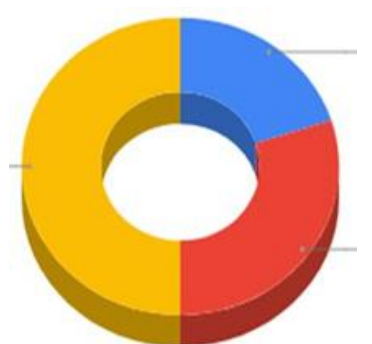

Fig. 4. \% annual demand of $A B C$ analysis 
Volume-3, Issue-9, September-2020

\section{IJRESM journals.resaim.com/ijresm | ISSN (Online): 2581-5792 | RESAIM Publishing}

B. Result for HML analysis

Table 5

The result of HML analysis

\begin{tabular}{|c|c|c|c|c|}
\hline Category & $\begin{array}{c}\text { Annual } \\
\text { Usage }\end{array}$ & $\begin{array}{c}\text { \% Annual } \\
\text { Usage }\end{array}$ & $\begin{array}{c}\text { Annual } \\
\text { Demand }\end{array}$ & $\begin{array}{c}\text { \% } \\
\text { Annual Demand }\end{array}$ \\
\hline H & 64750 & 4.56 & 1 & 10 \\
\hline M & 413715.2 & 29.15 & 3 & 30 \\
\hline L & 940971 & 66.29 & 6 & 60 \\
\hline Total & 1419436.2 & 100 & 10 & 100 \\
\hline
\end{tabular}

HML analysis based on annual usage percentage is illustrated in figure 5.

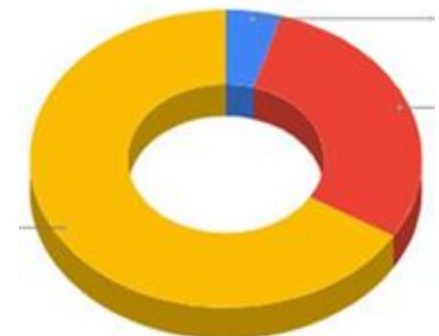

Fig. 5. Percent annual usage of HML analysis

HML analysis based on annual demand percentage is illustrated in figure 6.

\section{$\%$ Annual Demand}

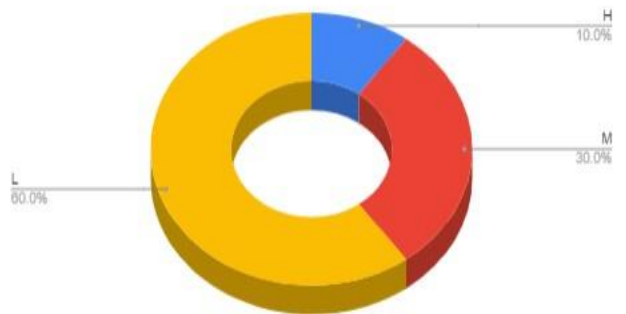

Fig. 6. Percent annual demand of HML analysis

\section{Conclusion}

In the assembling condition, the organization must keep up a harmony between basic Inventory-outs and limit Inventory expenses. From the analysis, we found that this examination encourages the organization to oversee Inventory adequately. It will assist with understanding the issues related with buying the expense of material Inventory and wellbeing Inventory. From this $\mathrm{ABC}$ analysis of assembling organization, A sort things have more yearly utilization costs so here 2 things have characterized under A class out of 10 things and just A sort things have more yearly utilization costs and make more Inventory coming up. So Economic Order Quantity and rerequest level will be determined for these A kind thing consequently diminish Inventory and yearly utilization cost. HML analysis is as like ABC examination, which implies that $\mathrm{H} \& \mathrm{M}$ things ought not to be requested more than the necessary amount.

\section{Acknowledgement}

First of all, I extend my heartfelt gratitude to Mr. M. D. Jaybhaye, Associate Professor, Department of Manufacturing Engineering and Industrial Management, for his exemplary guidance and valuable suggestions, which helped me in effectively developing my work. We also extend our thanks to our faculty members, family members and friends for their motivation and moral support towards successfully accomplish this work.

\section{References}

[1] Mitra, S, Pattanayak, S. K., \& Bhowmik, P. (2013). Inventory control using $\mathrm{ABC}$ and $\mathrm{HML}$ analysis - A case study on a manufacturing industry. International Journal of Mechanical and Industrial Engineering, 3(1), 37-42.

[2] Kumar, P., \& Anas, M. (2013). An ABC analysis for the multiple products inventory management case study of scooters India limited. IJREAT International Journal of Research in Engineering \& Advanced Technology, 1(5), 1- 6.

[3] Chen, W. Z., Hung, L. C., Fu, F. E., \& Peng, S. S. (2012). An abc analysis model for the multiple products inventory control - A case study of company X. Proceedings of the Asia Pacific Industrial Engineering \& Management Systems Conference, pp. 495-503.

[4] Ravinder, H., \& Misra, R. B. (2014). ABC analysis for inventory management: Bridging the gap between research and classroom. American Journal of Business Education - Third Quarter, 7(3), 257-264.

[5] Hatefi, S. M., Torabi, S. A., \& Bagheri, P. (2014). Multicriteria ABC inventory classification with mixed quantitative and qualitative criteria. International Journal of Production Research, 52(3), 776-786.

[6] Verma, P. (2010). Inventory Management of Selected Shipyard Companies in India, Ph.D. thesis, Saurashtra University.

[7] Rambabu, B., \& Malyadri, G. (2014). A study on inventory management at Amara Raja Electronics Ltd, Tirupati. Global Journal for Research Analysis, 3(1), 44-47. 